It is my pleasant duty to thank Mr. A. H. Levy for his usual benevolent criticism and help with the manuscript.

\title{
REFERENCES
}

1. Pines.-Sclerosis of the Retinal Vessels. Brit. Jl. of Ophthal., March, 1929.

2. BAILliart. - La circulat. ret. 1923.

3 Elliot.-The ret. pulse. Brit. Jl. of Ophthal., 1921.

4. Jauss.-Ueber den gefer. Arch.f. Ophthal., p. 437, 1929.

5. Kurzes Handb. der Ophthal., Vol. IV. J. Springer.

6. Eyster.-The clinical aspect of venous pressure. 1929. The MacMoll Cy.

7. BINTON.-Opift. Pflüger's Arch., Vol. CXXIX, p. 189, 1909.

8. SONDERMAN.-Arch. of Ophtal., p. 120, 1930.

9. Pines. Retinitis nephritica or albuminurica. Brit. Jl of Ophthal., 1931.

10. Harrington Sainsbury. - State of the arteries. Brit. Med. Jl., February, 1929.

11. Villaret.-La press. vein periph. Paris, 1930.

12. FRY.-Central vein of the retina. Arch. of Ophthal., 1930.

\section{LIGHTRESERVE FOR OCCUPATIONS IN SIGHT-SAVING CLASSES}

\author{
BY
}

\author{
Prof. R. A. KAZ, M.D.
}

(LENINGRAD)

IN young patients with defective sight much depends on physiotherapeutical treatment, and the steadiness of their improvement depends largely on the conditions of the sight-saving classes, and above all-on the sufficiency of light for occupations. The same, as I already said, is indicated by my measurer of lightreserve* through which the study or work are almost as visible as without the measurer. We, in the north, during the dark winter days find it is more difficult than in the south to receive with the measurer a positive result, particularly in feebly-seeing children with strong spectacles, which by themselves absorb a certain amount of light. So it is easy to conceive the various symptoms which can here arise-the symptoms of overfatigue of the eyes.

If, in spite of the last degree of fatigue which appears already in the breakdown of the eyes, in their burning, in temporal covering the object of reading, in endless winking of the eyelids, the worker

* The idea of reservelight as conservator of the working eyes was first put forward by me 40 years ago ("Reservelight as measurer of the sufficiency of the light for occupations." Vracz, 1897, No. 27), and for the last time-26 years ago ("Die Lichtvorratsprüfung in der Schulphotometrie." Internat. Arch. f. Schulhygiene, 1911). Of the works undertaken with my measurer of the lightreserve the investigations of $G$. J. Schoute merit particular attention which as a result of the School Commission determinated the sufficiency of light in the public-schools of Amsterdam (Geneeskundige Bladen, 1902). 
yet continues his occupation, he will try and redress the swollen muscles of the eyes by repeated pressure of the lids and by vigorous movements of the globes from side to side, he will apply his cool hand to his burning eyes, will rub them with the fingers-and he continues to read, and thereupon the eyes again renounce work; once more he is repeating all these manipulations, compelling them to go on working. In this case will already arise not only fatigue of the eyes, but an overfatigue, that is such a state which does not disappear after a more or less short rest, but leaves certain traces.

The journalists who use their eyes for work all night, notwithstanding the strain of the eyes and the noise in the head: the clerks, who are seated the whole day at endless rows of figures and letters often under insufficient light; the hypermetropes, who try to dispense with spectacles and work with frowning and winking eyes; the myopes, who bend down over their work until it is done; the feebly-seeing children, who work with insufficient lightreserve, because their spectacles take away a part of light or because the lighting of their place of work is insufficient-all these persons bear in their eyes the traces of overfatigue.

Photophobia is the first symptom of overfatigue of the eyes. Many wear in the street smoke or blue glasses at a time when they really need spectacles for work; instead of removing the cause of the overfatigue of the eyes, the strain of the accommodative muscle, they treat its symptom. Epiphora is the second symptom. With removal of overfatigue of the eyes from insufficiency of light or of same by working without spectacles or with faulty spectacles epiphora disappears. The third symptom-red eyelids, and sometimes also chalazia ${ }^{1}$ on the lids. The fourth-incessant winking of the eyelids. The fifth-twitching of the eyelids. The sixth-itching, burning and the sense of pressure in the eyelids. The seventh-heat in the eyes and the feeling as if a foreign body were under the eyelids. The eighth-glueing of the eyelids after sleep. This indicates an inflammatory condition of the lids, but it can disappear without treatment, if the causes of overfatigue of the eyes are removed. The ninth symptom-" flying spots," which are also visible to the untired eye, if we look through a small opening at a light surface. In myopia the "spots" are noticed by the unfatigued eye also without such adaptation; but in fatigue they become very obvious and in some cases lead to a fear of organic disease (see the history of the girl S. K.). The tenth symptom-rapid fatiguing of all the apparatus, which takes part in the act of vision : of the retina, of the accommodative muscle and of the convergent muscles. The eleventh symptom-extraordinary irritability of this apparatus. The twelfth symptom-headache.

All these symptoms from working in insufficiency of light can be 
eliminated by the measurer of the lightreserve, and that is why I concluded my communication on lightreserve ${ }^{2}$ with the following words: "Taking into consideration that the civilized world more and more accepts the importance of saving the health and not least that of the eyes, that the choice of localities for schools is more dependent on the lighting facilities now than before, that more and more it becomes usual to employ the photometer as the lightreservoir and that this sanitary control is also adopted by many works here and there; starting from these points, we can say that the time is not far off, when in the schools and workshops we ought to pay as much attention to the sufficiency of the light as to the temperature of the air and the duration of the work."

The same certainly concerns the sight-saving classes, where the equal displacement ${ }^{3}$ is necessary as in normal schools.

That displacement must be produced in two directions: (1) written on the board is deciphered by the scholar without blinking (a) from his own place, (b) only at displacement to one of the front benches and (c) is not deciphered from the front benches at all, and (2) separate words in the book are made out by the scholar also through the smoked glasses of the measurer of lightreserve $(a)$ at his table, $(b)$ only at displacement nearer to the window and (c) are not made out even at the window. In the case of $(c)$, where the oculist cannot help, the engineer has to step in. In the most difficult cases one will be obliged to apply to that adaptation which I have presented in my article "Gewalztes Prismenglas und versteckbare Pultlampen zur Verbesserung der Beleuchtung in den Schulen" (Wochenschrift für Therapie und Hygiene des Auges, 1914, No. 29).

Here I cite from this article only the three following figures.

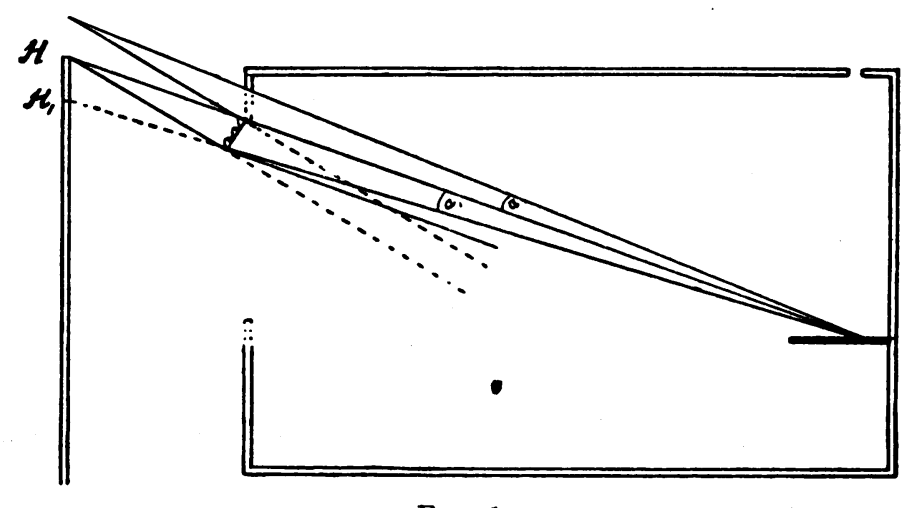

Fig. 1.

Rolling prism glass for reinforcement of the day-light in the depth of the schoolroom. 


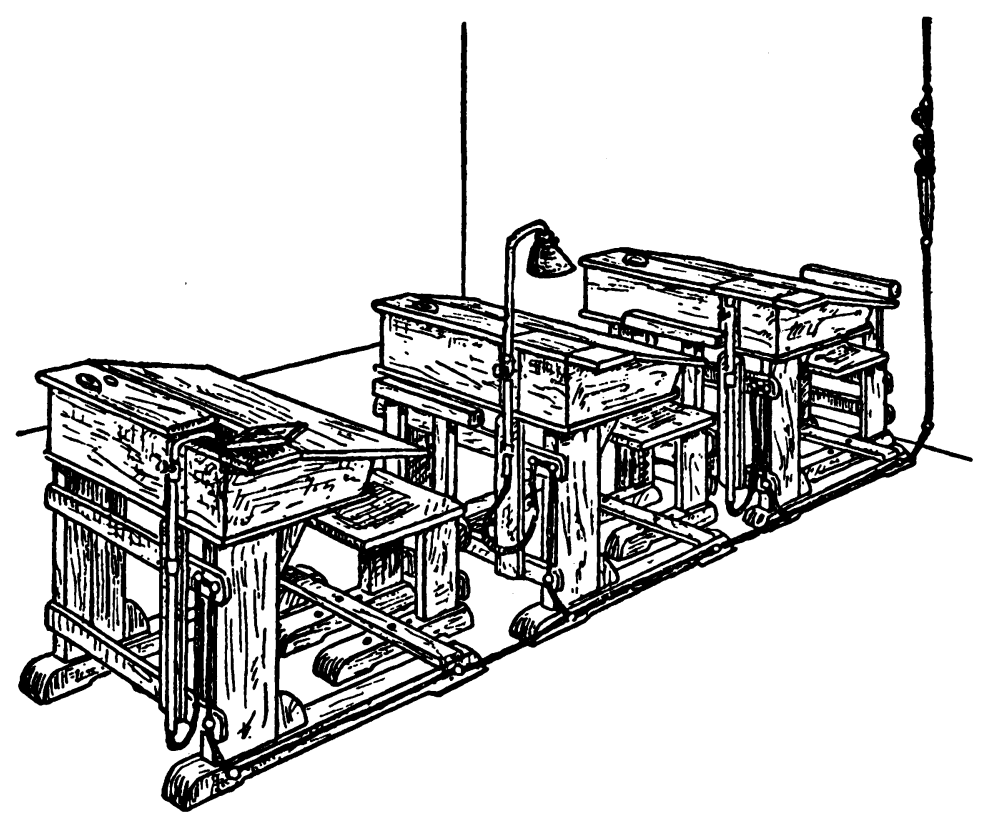

FIG. 2.

Individual school-lighting with concealed heating-lamps.

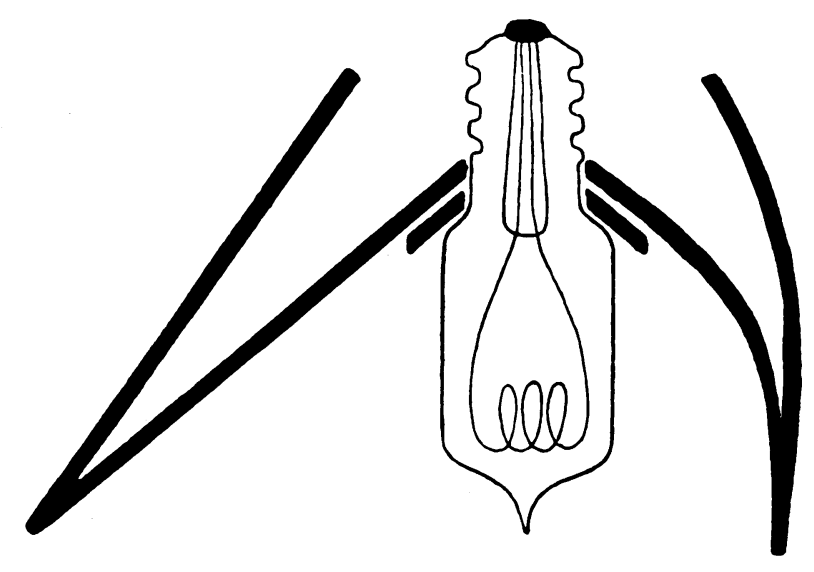

FIG. 3.

The shade of the concealed lamps. Natural size.

\section{REFERENCES}

1. KAZ, R. A.-About lightreserve for occupations in family and in school. Measurer of the lightreserve. Vracz, 1900, No. 24.

2. On lightreserve of the working tables for the safe-keeping of the eyes in the schools and workshops. Wiestn. Oft., Febr.. 1909.

3. On displacement of the scholars by vision. Vracz, 1903, No. 1. 